\title{
Phylogenetic relationships of Pseudomonas putida strains deduced from the nucleotide sequences of gyrB, rpoD and 165 rRNA genes
}

\author{
Satoshi Yamamotot and Shigeaki Harayama \\ Author for correspondence: Satoshi Yamamoto. Tel: +81 43203 0226. Fax: +81432482109. \\ e-mail : yamamotost@nichirei.co.jp
}

Marine Biotechnology Institute, 3-75-1 Heita, Kamaishi, Iwate 026, Japan

\begin{abstract}
Phylogenetic analysis of 20 Pseudomonas strains (Pseudomonas putida, Pseudomonas fluorescens and Pseudomonas chlororaphis) was conducted by using the nucleotide sequences of the genes for 16S rRNA, DNA gyrase B subunit (gyrB) and RNA polymerase $\sigma^{70}$ factor ( $\left.r p o D\right)$, which have been determined by the direct sequencing of PCR-amplified fragments. On the basis of gyrB and $r p o D$ sequences, these strains were split into two major clusters: one including the type strain of $P$. putida and all biovar $A$ strains and the other including all $P$. putida biovar $B$ strains, $P$. fluorescens strains and the $P$. chlororaphis strain. In the phylogenetic tree reconstructed from the 165 rRNA sequences including variable regions, $P$. putida biovar $A$ and $B$ strains were not separated into two independent clusters, whereas in the phylogenetic tree reconstructed from the 165 rRNA sequences excluding the variable region sequences, these strains were separated into $P$. putida biovar $A$ and biovar $B$ clusters. The pairwise distances estimated from the variable regions of 165 rRNA correlated poorly with the synonymous distances estimated from the gyrB and rpoD genes. On the other hand, a highly significant correlation was observed between the pairwise distances estimated from the non-variable regions of $16 \mathrm{~S}$ rRNA and the synonymous distances from gyrB and rpoD genes. Consequently, only the 165 rRNA sequences in the non-variable regions should be used for the phylogenetic analysis. The gyrB and rpoD analyses showed the necessity for the reclassification of $P$. putida biovar $B$ strains.
\end{abstract}

Keywords: gyrB, rpoD, 16S rRNA, Pseudomonas, PCR

\section{INTRODUCTION}

One goal of systematics is the establishment of a phylogeny-based classification system (31), and the nucleotide sequences of various genes, especially those of small-subunit (SSU) rRNA, are widely used for such a purpose $(27,41)$. A comparison of the SSU rRNA sequences from various organisms has resulted in many new discoveries, including that of the Archaea, a group of prokaryotes that is separated from the Bacteria. More than 2000 bacterial SSU rRNA (16S

\footnotetext{
† Present address: Food Science Laboratory, Research and Development Center, Nichirei Corporation, Shiminato 9, Mihama-Ku, Chiba 261, Japan.

The GenBank/EMBLDDBJ accession numbers for the sequences reported in this paper are: 16S rRNA genes, D37923-D37925, D83788 and D85991D86004; gyrB, D37926, D37297 and D86005-D86019; rpoD, D86020D86036.
}

rRNA) sequences are now available from the Ribosomal Database Project (RDP) (20), and a 16S rRNAbased phylogenetic tree of the Bacteria has been constructed (27). The current recommendation for bacterial taxonomy is the inclusion of 16S rRNA sequence data in the description of a new genus (35).

However, the results of the SSU rRNA-based analysis often do not correlate with the DNA reassociation values determined by DNA hybridization which has been used as the criterion for definition of bacterial species $(12,34)$. In these cases, it seems that the resolution of SSU rRNA-based analysis is low due to the small numbers of substitutions between compared SSU rRNA sequences. To resolve the phylogenetic relationships of closely related organisms, it would be necessary to use other gene sequences which provide a higher resolution than that of SSU rRNA. In this study, we examined the phylogenetic relationships of 
twenty Pseudomonas strains ( $P$. putida, $P$. fluorescens and $P$. chlororaphis) on the basis of the nucleotide sequences of their genes for 16S rRNA, DNA gyrase B subunit $(g y r B)$ and $\sigma^{70}$ factor $(r p o D)$. DNA gyrase is the enzyme responsible for introducing negative supercoils into bacterial chromosomes and plays a crucial role in the replication of chromosomes (39), while the $\sigma^{70}$ factor is one of the sigma factors that confers promoter-specific transcription initiation on RNA polymerase (19). Both DNA gyrase and the $\sigma^{70}$ factor are essential for cell survival in bacteria, and horizontal transmission of these genes may be as rare as that of rRNA genes. Protein-encoding genes have been reported to evolve much faster than rRNAs (26); thus a phylogenetic analysis using the gyr $B$ and $r p o D$ sequences was expected to provide higher resolution than one using 16S rRNA sequences.

\section{METHODS}

Bacterial strains. $P$. putida strains IFO $14164^{\mathrm{T}}[=\mathrm{ATCC}$ 12633, biovar A (36)], IFO 14671, IFO 3738 (=ATCC 8209, 'Pseudomonas ovalis'), ATCC 11172 [biovar A (21)], ATCC 17484 [biovar B (1)], ATCC 17522 [biovar B (36)], ATCC 23973 (9), JCM 6156 [= ATCC 33015, mt-2 (40)], NCIMB 9816(1), A10L (32), BH (37), EST1033 [a derivative of EST1001 (25)], KF715 (13), PpG7 [= ATCC 17485, biovar A (1, 44)], K23-1 (22) and PB4 (43), P. fluorescens strains IAM 12022 ${ }^{\mathrm{T}}$ [= ATCC 13525 (36)], DSM 50108 [= ATCC 17482 (36)] and NCIMB 9815, and P. chlororaphis strain IFO $3904^{\mathrm{T}}$ [= ATCC 9446 (36)] were used. The ATCC, DSM, IAM, IFO, JCM and NCIMB strains were purchased respectively from American Type Culture Collection (Rockville, MD, USA), Deutsche Sammlung von Mikroorganismen und Zellkulturen (DSMZ; Braunschweig, Germany), Institute of Applied Microbiology at University of Tokyo, (Tokyo, Japan), Institute for Fermentation, Osaka (Osaka, Japan), Japan Collection of Microorganisms at Riken (Saitama, Japan), and National Collections of Industrial and Marine Bacteria (Aberdeen, UK).

Preparation of chromosomal DNA. Each bacterial sample was grown aerobically in nutrient broth at $30^{\circ} \mathrm{C}$, and chromosomal DNA was prepared from the cells of overnight cultures, after being washed and resuspended in a TE buffer (10 $\mathrm{mM}$ Tris/ $\mathrm{HCl}$ containing $1 \mathrm{mM}$ EDTA, $\mathrm{pH} \mathrm{7.5),} \mathrm{by} \mathrm{the}$ method described by Johnson (15).

PCR amplification and direct sequencing of rpoD. A set of PCR primers, $70 \mathrm{~F}$ and $70 \mathrm{R}$, were used to amplify $r p o D$ gene fragments. The sequence of 70F [5'-ACGACTGACCCGGTACGCATGTA(TC)ATG(CA)G(ATGC)GA(AG)ATGGG(ATGC)AC(ATGC)GT-3', mixed bases being indicated in parentheses], and that of 70R [5'-ATAGAAATAACCAGACGTAAGTT(ATGC)GC(TC)TC(ATGC)ACCAT(CT)TC(CT)TT(CT)TT-3'] were designed from the amino acid sequences in the regions of RNA polymerase $\sigma^{70}$ factors which are conserved between Buchnera aphidicola, Escherichia coli K-12 (4), Salmonella typhimurium and Pseudomonas aeruginosa: namely, MYMREMGTV (positions $100-108$ of E. coli $\sigma^{70}$ ) and KKEMVEAN (positions 376-383 of $E$. coli $\left.\sigma^{70}\right)$, respectively. The first 23 nucleotides from the $5^{\prime}$ ends of the PCR primers are not degenerate, and these regions were used for priming the nucleotide sequencing as described below. PCR amplification was performed with a DNA thermal cycler 480 (Perkin-Elmer) by using a PCR reaction buffer (Perkin-Elmer) containing each of the deoxynucleoside triphosphates at a concentration of $200 \mathrm{mM}$, each of the primers at a concentration of $1 \mu \mathrm{M}$, $1 \mu \mathrm{g}$ target DNA and $2.5 \mathrm{U}$ Taq DNA polymerase in a total volume of $10 \mu \mathrm{l}$. A total of 30 amplification cycles were performed with template DNA: denaturation at $94^{\circ} \mathrm{C}$ for $1 \mathrm{~min}$, primer annealing at $59^{\circ} \mathrm{C}$ for $45 \mathrm{~s}$, and primer extension at $72^{\circ} \mathrm{C}$ for $2 \mathrm{~min}$. By using PCR primers $70 \mathrm{~F}$ and $70 \mathrm{R}$, DNA segments of about $800 \mathrm{bp}$ were amplified from all the Pseudomonas strains examined. The amplified products were purified by preparative gel electrophoresis on $1.4 \%$ low-melting-temperature agarose (NuSieve GTG, FMC Bioproducts) according to the method described by Sambrook et al. (30) before the amplified fragments were sequenced. The total nucleotide sequences of the amplified fragments were determined by using sequencing primers 70Fs (5'-ACGACTGACCCGGTACGCATGTA-3'), and 70Rs (5'-ATAGAAATAACCAGA CGTAAGTT-3'), which correspond to the first 23 nucleotides of PCR primers $70 \mathrm{~F}$ and $70 \mathrm{R}$, respectively. The sequencing reaction was conducted by using a Taq DyeDeoxy Terminator cycle sequencing kit (Perkin-Elmer) according to the manufacturer's instructions, and the products were analysed with a 373A DNA sequencer (Perkin-Elmer).

PCR amplification and direct sequencing of the gyrB and 165 rRNA genes. The gyr $B$ fragments corresponding to positions 335-1482 of the $E$. coli K-12 gyrB sequence (42) were amplified from DNA of 20 Pseudomonas strains and sequenced as described previously (43). Partial nucleotide sequences of the 16S rRNA genes of 20 Pseudomonas strains corresponding to positions $37-1370$ of the E. coli $\mathrm{K}-12$ sequence (3) containing variable regions V1-V8 were also determined directly from the PCR fragments according to the method of Edwards et al. (8).

Data analysis. The nucleotide sequences of $16 \mathrm{~S}$ rRNA and the translated amino acid sequences of $g y r B$ and $r p o D$ were aligned by using the CLUSTAL w computer program (38). The gyr $B$ and $r p o D$ sequences were aligned based on the amino acid sequences of their products, while $16 \mathrm{~S}$ rRNA sequences were aligned based on their secondary structures. The numbers of synonymous sites and synonymous substitutions between all possible pairs of the $\operatorname{gyr} B$ and $r p o D$ genes were obtained by applying the method of Nei \& Gojobori (23), using the MEGA computer program (17). The correction for multiple substitution was made by the Jukes-Cantor formula (16). Evolutionary trees were constructed with the PHYLIP program package (10), using the neighbour-joining method (29) with genetic distances computed by using the Jukes-Cantor model (16). Two types of phylogenetic trees were constructed from the 16S rRNA sequences: (i) the tree based on the 16S rRNA sequences including the sequences of variable regions V1-V8; (ii) the tree based on the $16 \mathrm{~S}$ rRNA sequences excluding the variable regions.

\section{RESULTS}

\section{Comparison of the phylogenetic structures deduced from the nucleotide sequences of the gyrB, rpoD and 16S rRNA genes}

The partial nucleotide sequences of the $g y r B$, $r p o D$ and 16S rRNA genes from 20 Pseudomonas strains were determined, and phylogenetic trees based on these data were constructed by the neighbour-joining method (Fig. 1) using the genetic distances adjusted by the Jukes-Cantor formula for multiple substitutions 


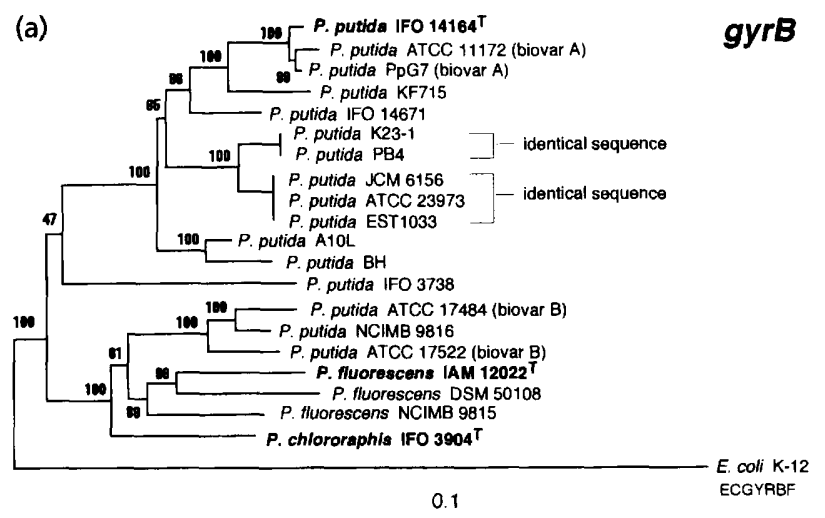

(b) $\quad 100 \Gamma^{P}$. puttda IFO $141644^{\top}$

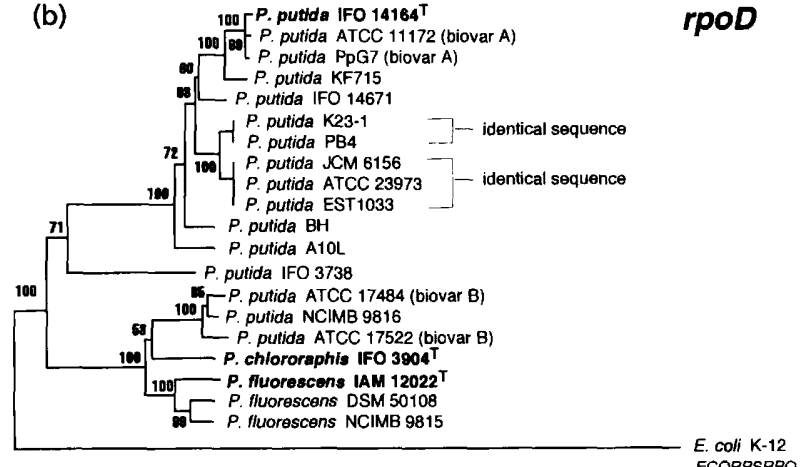
ECORPSRPO
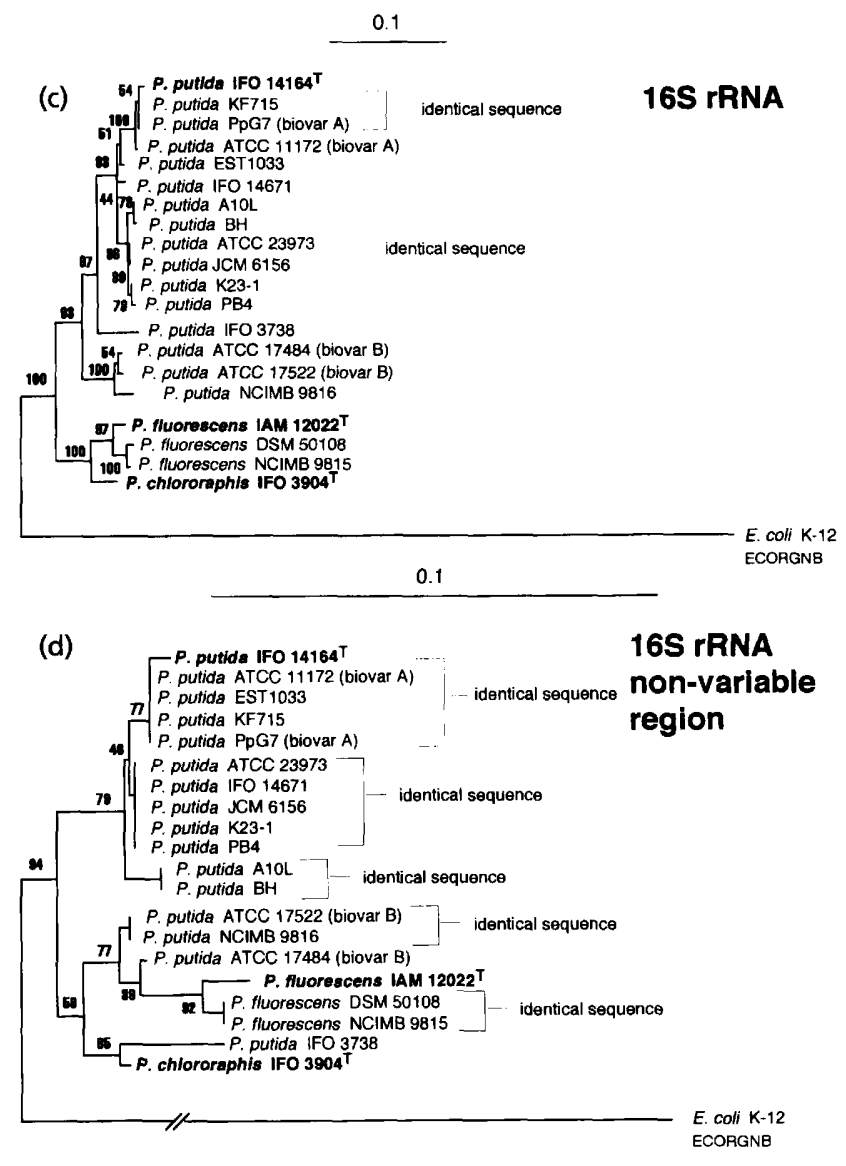

0.01
(Tables 1 and 2). The topology of the gyr $B$ - and $r p o D$ based trees was comparable. In these trees, Pseudomonas strains were grouped into two clusters, the first one containing $13 P$. putida strains including all the biovar A strains, while the second one contained the remaining $P$. putida strains including all the biovar B strains, all the $P$. fluorescens strains, and the $P$. chlororaphis strain.

The topologies of the trees reconstructed from the $16 \mathrm{~S}$ rRNA sequences including or excluding the sequences of variable regions were very different from each other (Fig. 1c, d). When the total 16S rRNA sequences were used for the analysis, Pseudomonas strain were divided into two major clusters, the cluster of $P$. putida strains and the cluster of the $P$. fluorescens and $P$. chlororaphis strains. Phylogenetic relationships between the $P$. putida strains were also largely different from those of the $g y r B$ - and $r p o D$-based trees. On the other hand, when the sequences of non-variable regions were used for the analysis, $P$. putida strains were split into two independent clusters as in the $\operatorname{gyr} B$ - and $r p o D$-based trees. However, the detailed topology of the tree based on the 16S rRNA non-variable region was also different from that of the $g y r B$ - and $r p o D$-based trees (e.g. position of $P$. putida IFO 3738 and EST1033). These topological differences between the $\operatorname{gyr} B$ - and $r p o D$ based trees and the 16S-rRNA-based trees were also observed when the trees were reconstructed by using the maximum-parsimony method (11) and unweighted pair group method with averages (UPGMA) (33).

\section{Comparison of the genetic distances in the gyrB, rPoD and 165 rRNA genes}

Most of the base substitutions in the gyr $B$ and $r p o D$ genes were synonymous, i.e. did not result in amino acid changes. For example, 185 nucleotide substitutions including 3 gaps were observed between the gyr $B$ genes in strains NCIMB 9815 and K23-1. Of these, only 25 contributed to the amino acid substitution or to the introduction of a gap. The syn-

Fig. 1. Phylogenetic trees of 20 Pseudomonas strains based on the nucleotide sequences of the $g y r B$ (a), rpoD (b) and $16 \mathrm{~S}$ rRNA genes $(c, d)$. Two types of phylogenetic trees were reconstructed from the 165 rRNA sequences: the tree based on the total 165 rRNA sequences including the sequences of variable regions ( $1329 \mathrm{bp}$ ) (c) and the tree based on the partial 165 rRNA sequences without the sequences of variable regions (1012 bp) (d). The trees were constructed by using the neighbour-joining method, and genetic distances were computed by the Jukes-Cantor model. The scale bar indicates the genetic distance of 0.1 or 0.01 . The number shown next to each node indicates the percentage bootstrap value of 1000 replicates. The sequences from $E$. coli $\mathrm{K}-12$ were treated as the outgroup. The topological characteristics of the gyrB- and $r p o D$-based phylogenetic trees produced by the neighbourjoining method, the maximum-parsimony method and the unweighted pair group with averages (UPGMA) were almost identical (data not shown). However, the topological characteristics of the 16S rRNA-based trees produced by these three methods were slightly different from each other. 
Table 1. Evolutionary distances between gyrB and rpoD sequences

The values on the upper right and the lower left are the evolutionary distances between $g y r B$ sequences and between $r p o D$ sequences, respectively. Both values were corrected by the Jukes-Cantor formula (16) for multiple substitutions.

\begin{tabular}{|c|c|c|c|c|c|c|c|c|c|c|c|c|c|c|c|c|c|c|c|c|c|}
\hline Strain & 1 & 2 & 3 & 4 & 5 & 6 & 7 & 8 & 9 & 10 & 11 & 12 & 13 & 14 & 15 & 16 & 17 & 18 & 19 & 20 & 21 \\
\hline 1 IFO $14164^{\mathrm{T}}$ & & $0 \cdot 014$ & 0.009 & 0.062 & $0 \cdot 153$ & 0.084 & $0 \cdot 084$ & 0.084 & 0.090 & $0 \cdot 090$ & 0.076 & 0.097 & 0.053 & 0.171 & $0 \cdot 163$ & $0 \cdot 163$ & 0.168 & $0 \cdot 151$ & $0 \cdot 167$ & 152 & $0 \cdot 315$ \\
\hline 2 ATTC 11172 & 0.010 & & 0.009 & 0.065 & 0.154 & 0.090 & 0.090 & 0.090 & 0.095 & 0.095 & 0.078 & $0 \cdot 101$ & 0.060 & 0.176 & $0 \cdot 166$ & $0 \cdot 168$ & 0.172 & $0 \cdot 158$ & 0.172 & 157 & $0 \cdot 327$ \\
\hline 3 PpG7 & 0.009 & 0.006 & & 0.060 & 0.149 & 0.084 & 0.084 & 0.084 & 0.089 & 0.089 & 0.074 & 0.095 & 0.054 & $0 \cdot 167$ & $0 \cdot 159$ & 0.159 & 0.164 & $0 \cdot 152$ & $0 \cdot 167$ & 146 & 0.321 \\
\hline 4 IFO 14671 & 0.076 & 0.074 & 0.073 & & $0 \cdot 149$ & 0.069 & 0.069 & 0.069 & 0.070 & 0.070 & 0.063 & 0.074 & 0.067 & 0.166 & $0 \cdot 156$ & $0 \cdot 153$ & $0 \cdot 164$ & $0 \cdot 143$ & $0 \cdot 167$ & 152 & 0.317 \\
\hline 5 IFO 3738 & 0.254 & 0.256 & $0 \cdot 254$ & 0.237 & & 0.152 & $0 \cdot 152$ & $0 \cdot 152$ & $0 \cdot 153$ & $0 \cdot 153$ & $0 \cdot 138$ & 0.152 & $0 \cdot 168$ & $0 \cdot 140$ & 0.146 & 0.142 & 0.167 & 0.154 & 0.175 & 149 & 0.334 \\
\hline $6 \mathrm{JCM} 6156$ & 0.080 & 0.077 & 0.076 & 0.059 & $0 \cdot 253$ & & 0.000 & 0.000 & 0.027 & 0.027 & $0 \cdot 066$ & 0.079 & 0.087 & $0 \cdot 172$ & $0 \cdot 158$ & $0 \cdot 161$ & $0 \cdot 164$ & $0 \cdot 161$ & 0.177 & 152 & $0 \cdot 315$ \\
\hline 7 ATCC 23973 & $0 \cdot 080$ & 0.077 & 0.076 & 0.059 & $0 \cdot 253$ & 0.000 & & 0.000 & 0.027 & 0.027 & $0 \cdot 066$ & 0.079 & 0.087 & 0.172 & $0 \cdot 158$ & $0 \cdot 161$ & $0 \cdot 164$ & $0 \cdot 161$ & $0 \cdot 177$ & 152 & $0 \cdot 315$ \\
\hline 8 EST1033 & 0.080 & 0.077 & 0.076 & 0.059 & $0 \cdot 253$ & 0.000 & 0.000 & & 0.027 & 0.027 & 0.066 & $0 \cdot 079$ & 0.087 & 0.172 & $0 \cdot 158$ & $0 \cdot 161$ & $0 \cdot 164$ & $0 \cdot 161$ & 0.177 & 152 & 0.315 \\
\hline $9 \mathrm{~K} 23-1$ & 0.081 & 0.078 & 0.077 & 0.058 & $0 \cdot 258$ & 0.023 & 0.023 & 0.023 & & 0.000 & $0 \cdot 068$ & 0.082 & 0.092 & 0.171 & $0 \cdot 159$ & $0 \cdot 157$ & $0 \cdot 164$ & $0 \cdot 155$ & $0 \cdot 179$ & 0 & $0 \cdot 314$ \\
\hline 10 PB4 & 0.081 & 0.078 & 0.077 & 0.058 & 0.258 & 0.023 & 0.023 & 0.023 & 0.000 & & 0.068 & 0.082 & 0.092 & $0 \cdot 171$ & $0 \cdot 159$ & $0 \cdot 157$ & 0.164 & $0 \cdot 155$ & 0.179 & 0.150 & $0 \cdot 314$ \\
\hline $11 \mathrm{~A} 10 \mathrm{~L}$ & $0 \cdot 102$ & $0 \cdot 101$ & 0.096 & 0.080 & $0 \cdot 225$ & 0.084 & 0.084 & 0.084 & 0.081 & 0.081 & & 0.032 & 0.078 & $0 \cdot 154$ & $0 \cdot 146$ & $0 \cdot 143$ & $0 \cdot 154$ & 0.137 & 0.159 & 0.138 & $0 \cdot 302$ \\
\hline $12 \mathrm{BH}$ & 0.078 & 0.077 & 0.076 & 0.062 & 0.234 & 0.065 & 0.065 & 0.065 & 0.063 & 0.063 & 0.059 & & 0.088 & $0 \cdot 168$ & $0 \cdot 163$ & 0.159 & $0 \cdot 168$ & $0 \cdot 147$ & 0.172 & 0.156 & 0.303 \\
\hline 13 KF715 & 0.043 & 0.041 & 0.039 & 0.058 & $0 \cdot 244$ & 0.078 & 0.078 & 0.078 & 0.077 & 0.077 & 0.098 & 0.077 & & 0.174 & $0 \cdot 171$ & $0 \cdot 165$ & $0 \cdot 170$ & $0 \cdot 157$ & $0 \cdot 176$ & $0 \cdot 161$ & 0.322 \\
\hline 14 ATCC 17484 & $0 \cdot 308$ & $0 \cdot 304$ & 0.302 & 0.312 & $0 \cdot 293$ & $0 \cdot 310$ & $0 \cdot 310$ & $0 \cdot 310$ & $0 \cdot 308$ & $0 \cdot 308$ & $0 \cdot 297$ & $0 \cdot 319$ & 0.317 & & $0 \cdot 055$ & 0.032 & 0.109 & $0 \cdot 102$ & $0 \cdot 111$ & 0.097 & $0 \cdot 326$ \\
\hline 15 ATCC 17522 & 0.315 & 0.314 & 0.310 & 0.321 & $0 \cdot 293$ & $0 \cdot 319$ & 0.319 & 0.319 & 0.317 & $0 \cdot 317$ & $0 \cdot 300$ & 0.325 & 0.325 & $0 \cdot 041$ & & 0.044 & 0.123 & $0 \cdot 104$ & 0.118 & $0 \cdot 102$ & $0 \cdot 310$ \\
\hline 16 NCIMB 9816 & 0.299 & $0 \cdot 293$ & 0.293 & 0.304 & 0.289 & $0 \cdot 299$ & 0.299 & 0.299 & 0.297 & $0 \cdot 297$ & $0 \cdot 286$ & $0 \cdot 310$ & $0 \cdot 308$ & 0.023 & 0.037 & & $0 \cdot 101$ & 0.092 & 0.107 & 0.093 & 0.319 \\
\hline 17 IAM $12022^{\mathrm{T}}$ & $0 \cdot 310$ & $0 \cdot 312$ & 0.305 & 0.316 & $0 \cdot 275$ & $0 \cdot 306$ & 0.306 & $0 \cdot 306$ & 0.299 & $0 \cdot 299$ & $0 \cdot 294$ & $0 \cdot 316$ & $0 \cdot 322$ & 0.126 & 0.118 & $0 \cdot 129$ & & 0.097 & 0.092 & $0 \cdot 121$ & 0.351 \\
\hline 18 DSM 50108 & $0 \cdot 301$ & 0.299 & 0.297 & $0 \cdot 306$ & $0 \cdot 265$ & $0 \cdot 306$ & $0 \cdot 306$ & $0 \cdot 306$ & $0 \cdot 305$ & $0 \cdot 305$ & $0 \cdot 279$ & $0 \cdot 310$ & $0 \cdot 306$ & $0 \cdot 117$ & $0 \cdot 108$ & 0.117 & 0.070 & & 0.097 & 0.114 & $0 \cdot 307$ \\
\hline 19 NCIMB 9815 & $0 \cdot 288$ & 0.288 & 0.284 & $0 \cdot 308$ & 0.281 & $0 \cdot 308$ & $0 \cdot 308$ & $0 \cdot 308$ & $0 \cdot 301$ & $0 \cdot 301$ & $0 \cdot 281$ & $0 \cdot 303$ & $0 \cdot 297$ & 0.113 & $0 \cdot 103$ & $0 \cdot 108$ & 0.072 & 0.038 & & $0 \cdot 130$ & $0 \cdot 340$ \\
\hline 20 IFO $3904^{\mathrm{T}}$ & 0.299 & $0 \cdot 300$ & 0.295 & $0 \cdot 304$ & 0.282 & $0 \cdot 300$ & 0.300 & $0 \cdot 300$ & $0 \cdot 302$ & 0.302 & 0.288 & $0 \cdot 308$ & 0.297 & $0 \cdot 123$ & $0 \cdot 107$ & 0.115 & $0 \cdot 129$ & 0.132 & 0.133 & & $0 \cdot 307$ \\
\hline 21 E. coli K-12 & 0.746 & 0.749 & 0.756 & 0.713 & 0.682 & 0.713 & 0.713 & 0.713 & 0.713 & 0.713 & 0.720 & 0.704 & 0.739 & 0.718 & 0.724 & 0.728 & 0.707 & 0.697 & 0.716 & 0.711 & \\
\hline
\end{tabular}

Table 2. Evolutionary distances between 165 rRNA sequences, and numbers of base substitution in helix 6 and helix 18 of $16 \mathrm{~S}$ rRNA

The values on the upper right are the evolutionary distances between the 16S rRNA, corrected by the Jukes-Cantor formula (16) for multiple substitutions. The values on the lower left are base substitutions occurring in helix 6 (34 bp) and helix 18 (61 bp). ND, Base substitution numbers between E. coli K-12 and Pseudomonas strains were not determined because of ambiguous positions of gaps.

\begin{tabular}{|c|c|c|c|c|c|c|c|c|c|c|c|c|c|c|c|c|c|c|c|c|c|}
\hline Strain & 1 & 2 & 3 & 4 & 5 & 6 & 7 & 8 & 9 & 10 & 11 & 12 & 13 & 14 & 15 & 16 & 17 & 18 & 19 & 20 & 21 \\
\hline 1 IFO $14164^{T}$ & & 0.002 & 0.002 & $0 \cdot 007$ & 0.018 & 0.011 & 0.011 & 0.006 & 0.010 & 0.009 & 0.012 & $0 \cdot 011$ & 0.002 & 0.022 & 0.022 & 0.025 & 030 & 035 & 034 & $\cdot 028$ & 0.174 \\
\hline 2 ATCC 11172 & $0 / 0$ & & 0.002 & 0.005 & 0.016 & 0.009 & 0.009 & 0.005 & 0.008 & 0.008 & 0.011 & 0.010 & 0.002 & 0.021 & $0 \cdot 021$ & 0.023 & 030 & 033 & 032 & 028 & $\cdot 174$ \\
\hline 3 PpG7 & $0 / 0$ & $0 / 0$ & & 0.005 & 0.016 & 0.009 & 0.009 & 0.005 & 0.010 & $0 \cdot 009$ & 0.011 & $0 \cdot 010$ & 0.000 & 0.022 & 0.022 & 0.025 & 0.030 & 033 & 0.032 & .028 & $0 \cdot 173$ \\
\hline 4 IFO 14671 & $0 / 6$ & $0 / 6$ & $0 / 6$ & & 0.014 & $0 \cdot 004$ & 0.004 & 0.005 & 0.005 & 0.005 & 0.005 & 0.006 & 0.005 & 0.020 & 0.020 & 0.022 & 0.036 & 0.036 & 0.036 & 0.033 & $\cdot 171$ \\
\hline 5 IFO 3738 & $0 / 6$ & $0 / 6$ & $0 / 6$ & $0 / 2$ & & 0.018 & 0.018 & 0.016 & 0.018 & $0 \cdot 018$ & 0.016 & 0.015 & 0.016 & 0.021 & 0.022 & 0.025 & 0.033 & 0.034 & 0.033 & 0.029 & 0.176 \\
\hline $6 \mathrm{JCM} 6156$ & $5 / 6$ & $5 / 6$ & $5 / 6$ & $5 / 0$ & $5 / 2$ & & 0.000 & 0.005 & 0.001 & 0.002 & 0.002 & 0.002 & 0.009 & 0.020 & 0.020 & 0.022 & 0.036 & 0.037 & 0.036 & 0.034 & $0 \cdot 169$ \\
\hline 7 ATCC 23973 & $5 / 6$ & $5 / 6$ & $5 / 6$ & $5 / 0$ & $5 / 2$ & $0 / 0$ & & 0.005 & 0.001 & 0.002 & 0.002 & 0.002 & 0.009 & 0.020 & 0.020 & 0.022 & 0.036 & 0.037 & 0.036 & 0.034 & $0 \cdot 169$ \\
\hline 8 EST1033 & $3 / 3$ & $3 / 3$ & $3 / 3$ & $3 / 3$ & $3 / 3$ & $2 / 3$ & $2 / 3$ & & 0.005 & 0.005 & 0.006 & $0 \cdot 005$ & 0.005 & 0.021 & 0.021 & 0.023 & 0.033 & 0.034 & 0.033 & 0.031 & 0.174 \\
\hline $9 \mathrm{~K} 23-1$ & $5 / 6$ & $5 / 6$ & $5 / 6$ & $5 / 0$ & $5 / 2$ & $0 / 0$ & $0 / 0$ & $2 / 3$ & & 0.001 & 0.002 & 0.003 & 0.010 & 0.019 & 0.019 & 0.021 & 0.036 & 0.038 & 0.037 & 0.033 & $0 \cdot 169$ \\
\hline 10 PB4 & $5 / 5$ & $5 / 5$ & $5 / 5$ & $5 / 1$ & $5 / 1$ & $0 / 1$ & $0 / 1$ & $2 / 2$ & $0 / 1$ & & 0.003 & 0.002 & 0.009 & 0.020 & $0 \cdot 020$ & 0.022 & 0.035 & 0.037 & 0.036 & 0032 & 0.170 \\
\hline $11 \mathrm{~A} 10 \mathrm{~L}$ & $5 / 6$ & $5 / 6$ & $5 / 6$ & $5 / 0$ & $5 / 2$ & $0 / 0$ & $0 / 0$ & $2 / 3$ & $0 / 0$ & $0 / 1$ & & 0.001 & 0.011 & 0.021 & 0.021 & 0.024 & 0.037 & 0.037 & 0.036 & 0.032 & 0.171 \\
\hline $12 \mathrm{BH}$ & $5 / 5$ & $5 / 5$ & $5 / 5$ & $5 / 1$ & $5 / 1$ & $0 / 1$ & $0 / 1$ & $2 / 2$ & $0 / 1$ & $0 / 0$ & $0 / 1$ & & 0.010 & 0.022 & 0.022 & $0 \cdot 025$ & 0.036 & 0.036 & 0.036 & 0.032 & 0.172 \\
\hline 13 KF715 & $0 / 0$ & $0 / 0$ & $0 / 0$ & $0 / 6$ & $0 / 6$ & $5 / 6$ & $5 / 6$ & $3 / 3$ & $5 / 6$ & $5 / 5$ & $5 / 6$ & $5 / 5$ & & 0.022 & 0.022 & 0.025 & 0.030 & 0.033 & 0.032 & 0.028 & 0.173 \\
\hline 14 ATCC 17484 & $4 / 6$ & $4 / 6$ & $4 / 6$ & $4 / 2$ & $4 / 4$ & $4 / 2$ & $4 / 2$ & $4 / 4$ & $4 / 2$ & $4 / 3$ & $4 / 2$ & $4 / 3$ & $4 / 6$ & & 0.002 & 0.008 & 0.026 & 0.028 & 0.028 & 0.027 & 0.171 \\
\hline 15 ATCC 17522 & $4 / 7$ & $4 / 7$ & $4 / 7$ & $4 / 3$ & $4 / 5$ & $4 / 3$ & $4 / 3$ & $4 / 5$ & $4 / 3$ & $4 / 4$ & $4 / 3$ & $4 / 4$ & $4 / 7$ & $1 / 1$ & & 0.005 & 0.028 & 0.029 & 0.029 & 0.028 & 0.172 \\
\hline 16 NCIMB 9816 & $4 / 12$ & $4 / 12$ & $4 / 12$ & $4 / 8$ & $4 / 10$ & $4 / 8$ & $4 / 8$ & $4 / 10$ & $4 / 8$ & $4 / 9$ & $4 / 8$ & $4 / 9$ & $4 / 12$ & $1 / 6$ & $0 / 5$ & & 0.032 & 0.033 & 0.033 & 0.029 & $0 \cdot 175$ \\
\hline 17 IAM $12022^{\mathrm{T}}$ & $11 / 0$ & $11 / 0$ & $11 / 0$ & $11 / 6$ & $11 / 6$ & $12 / 6$ & $12 / 6$ & $12 / 3$ & $12 / 6$ & $12 / 5$ & $12 / 6$ & $12 / 5$ & $11 / 0$ & $15 / 6$ & $15 / 7$ & $15 / 12$ & & 0.008 & $0 \cdot 007$ & $0 \cdot 014$ & 0.167 \\
\hline 18 DSM 50108 & $11 / 5$ & $11 / 5$ & $11 / 5$ & $11 / 8$ & $11 / 8$ & $12 / 8$ & $12 / 8$ & $12 / 5$ & $12 / 8$ & $12 / 7$ & $12 / 8$ & $12 / 7$ & $11 / 5$ & $15 / 8$ & $15 / 9$ & $15 / 14$ & $0 / 5$ & & 0.002 & $0 \cdot 014$ & $0 \cdot 173$ \\
\hline 19 NCIMB 9815 & $11 / 4$ & $11 / 4$ & $11 / 4$ & $11 / 7$ & $11 / 7$ & $12 / 7$ & $12 / 7$ & $12 / 4$ & $12 / 7$ & $12 / 6$ & $12 / 4$ & $12 / 6$ & $11 / 4$ & $15 / 7$ & $15 / 8$ & $15 / 13$ & $0 / 4$ & $0 / 1$ & & 0.014 & 0.173 \\
\hline 20 IFO $3904^{T}$ & $11 / 5$ & $11 / 5$ & $11 / 5$ & $11 / 10$ & $11 / 10$ & $12 / 10$ & $12 / 10$ & $12 / 7$ & $12 / 10$ & $12 / 9$ & $12 / 10$ & $12 / 9$ & $11 / 5$ & $15 / 10$ & $15 / 11$ & $15 / 12$ & $4 / 5$ & $4 / 5$ & $4 / 4$ & & $0 \cdot 169$ \\
\hline 21 E. coli $\mathrm{K}-12$ & ND & ND & ND & ND & ND & $\mathrm{ND}$ & ND & ND & ND & ND & ND & $\mathrm{ND}$ & ND & ND & ND & ND & ND & ND & ND & ND & ND \\
\hline
\end{tabular}

onymous distances calculated from the nucleotide substitution ratios at synonymous positions in the gyr $B$ and $r p o D$ genes were examined for all possible combinations of 20 Pseudomonas genes. A significant correlation between the synonymous distances in the gyr $B$ genes and those in the $r p o D$ genes was observed with a coefficient of correlation $(r)$ of 0.92 . This result was not unexpected, because it has been demonstrated that the synonymous substitution rate is constant for many chromosomal genes in many organisms, and can thus serve as a molecular clock of their evolution (18).

The base substitutions in the $16 \mathrm{~S}$ rRNAs were not randomly distributed, but observed only at 71 positions among the $1329 \mathrm{bp}$ of $16 \mathrm{~S}$ rRNA sequences, mainly in so-called variable regions $(53 / 71=74.6 \%)$. The substitutions were most frequently observed in helix 6 in variable region V1, and in helix 18 in variable 
(a) Variable regions

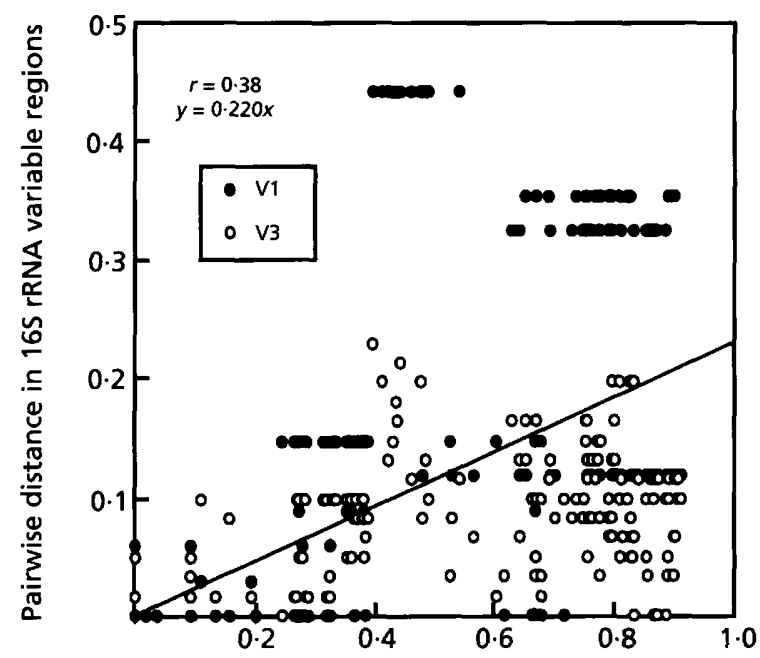

(b) Non-variable regions

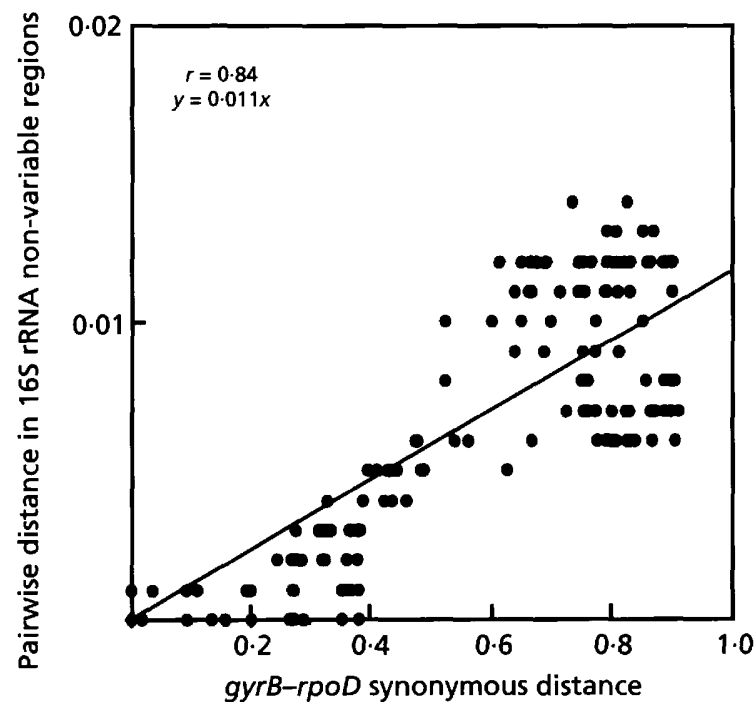

Fig. 2. Comparison between the genetic distances estimated from 16S rRNA and the synonymous distances estimated from the gyrB and $r p o D$ genes. The synonymous distances were obtained from the combined nucleotide sequences of the gyr $B$ and $r p o D$ genes (total of 1956 bases) by applying the method of Nei \& Gojobori (23). $r$ indicates the coefficient of correlation. (a) Comparison between the pairwise distances in the variable regions of 165 rRNA and the synonymous distances calculated from the gyr $B$ and $r p o D$ genes. The nucleotide substitutions in helix 6 and helix 18, corresponding to positions $65-104$ and 437-497, respectively, of $E$. coli $16 \mathrm{~S}$ rRNA according to the numbering system of Noller (24), were counted (Table 2). (b) Comparison between the genetic distances calculated from the non-variable regions of $16 \mathrm{~S}$ rRNA (1012 bp) and the synonymous distances calculated from the gyrB and $r p o D$ genes.

region V3 [helix numbers conform to the numbering system of Dams et al. (5)]: among 20 compared sequences, seven variations were found in helix 6 and 11 variations in helix 18 in contrast to $2-5$ variations in other variable regions. The base substitutions observed in the 34-bp-long helix 6 and in the 61 bp helix 18 are shown in Table 2 . The relationships between the pairwise distances among helix 6 and 18 sequences and the synonymous distances in the $g y r B$ and $r p o D$ genes are illustrated in Fig. 2(a), while the relationships between the pairwise distances in the non-variable regions of the $16 \mathrm{~S}$ rRNA and the synonymous distances in the gyrB and rpoD genes are shown in Fig. 2(b). There was a highly significant correlation between the genetic distances in the non-variable regions of the 16S rRNA and those in the gyrB and $r p o D$ genes whereas the correlation between the genetic distances in the variable regions of the $16 \mathrm{~S}$ rRNA and those in the $\operatorname{gyr} B$ and $r$ poD genes was much less significant. Therefore, it can be concluded that the base substitutions provoked in the variable regions of $16 \mathrm{~S}$ rRNA are not reliable as molecular evolutionary clocks. Consequently, only the sequences of non-variable regions of $16 \mathrm{~S}$ rRNA should be used for the phylogenetic analysis.

\section{DISCUSSION}

16S rRNA provides a scaffold for the assembly of ribosomal proteins into small subunits, and interacts with mRNA. Many base substitutions in 16S rRNA are located in a few helices called variable regions, indicating that regions other than the variable regions are crucial for ribosome functions. Generally, the multiple substitutions that are observed in the variable regions are mostly compensatory, thus keeping the helix structure unaltered $(7,14,28)$. Presumably the secondary structures of $16 \mathrm{~S}$ rRNA determined by the sequences in these variable regions are functionally important.

The genetic distances in the variable regions correlated poorly with the synonymous distances in the $\operatorname{gyr} B$ and $r p o D$ genes (Fig. 2). This observation suggests that the base substitutions in these helices are not due to cumulative successive point mutations, but may be caused by single-event mutations introducing multiple substitutions. Hence, the mutations in the variable regions should not be included in the calculation of the genetic distance. The base substitution rates in the $16 \mathrm{~S}$ rRNA outside the variable regions were very low between closely related bacteria, and a phylogenetic analysis based on the 16S rRNA sequences of the nonvariable regions may have insufficient resolution to distinguish bacterial species.

The topologies of phylogenetic trees reconstructed from GyrB and RpoD amino-acid sequences (obtained by translating gyr $B$ and $r p o D$ sequences) were slightly different from those of $g y r B$ and $r p o D$ trees (data not shown). When the amino acid sequences were used for the analysis, the phylogenetic information from synonymous substitutions was lost. The synonymous distances estimated from the $\operatorname{gyr} B$ and $r p o D$ genes were highly correlated, indicating that substitutions at the synonymous sites were not saturated in the present 
data set. Under such circumstances, a phylogenetic analysis which includes the synonymous substitutions may be more precise than that excluding them.

As already discussed, the phylogenetic distances calculated only by the synonymous substitution numbers in gyr $B$ were almost identical to those calculated by the synonymous substitution numbers in rpoD. However, if the total substitution numbers were used for the calculation, the phylogenetic distances evaluated by the $r p o D$ sequences were larger than those evaluated by the gyr $B$ sequences (Table 1, Fig. 1). The larger nucleotide substitution rates in $r p o D$ were due to larger non-synonymous substitution rates in $r p o D: 13.9 \%$ of the amino acid residues $(53 / 382)$ were changed among the $20 \mathrm{GyrB}$ sequences, while $38.3 \%(103 / 269)$ were changed among the $20 \mathrm{RpoD}$ sequences. It is known that different protein families have different amino acid substitution rates (6), and that such rates also vary in different regions within a single polypeptide. Therefore, it should be noted that the phylogenetic distance obtained from the total nucleotide substitutions is not an absolute measure of the divergence time.

\section{Delineation of $\boldsymbol{P}$. putida biovar B}

In this study, we have shown that $P$. putida biovar B strains are phylogenetically separated from the main cluster of $\boldsymbol{P}$. putida, including the type strain and biovar A strains. The following phenotypes are general characteristics of $P$. putida: Gram-negative rods with polar flagella, motile, produce fluorescein, unable to hydrolyse gelatin, give an egg-yolk reaction, do not denitrify, do not grow at $41^{\circ} \mathrm{C}$ and do not produce phenazine pigment. Strains of $P$. putida biovar B have been distinguished from biovar A mainly by their ability to grow on L-tryptophan and L-kynurenine (36). However, $P$. putida biovar B strains are more $P$. fluorescens-like in some respects. They can grow at $4{ }^{\circ} \mathrm{C}$ and can utilize a broader range of sugars than biovar A strains (36). Thus, the closer phylogenetic positions of the biovar B strains to $P$. fluorescens strains than to biovar A strains deduced from the analyses using $g y r B, r p o D$ and the non-variable region of $16 \mathrm{~S}$ rRNA seem to be consistent with their phenotypic characteristics.

Unclassified $P$. putida NCIMB 9816 formed a cluster with biovar B strains in the trees based on gyr $B$, rpoD and the non-variable region of 16S rRNA (Fig. 1). Biochemical characteristics of strain NCIMB 9816 determined by the Biolog system (2) were more similar to those of biovar B strains ATCC 17484 and ATCC 17522 (80 and $82 \%$ similarity, respectively) than to those of biovar A strain P. putida IFO $14164^{\mathrm{T}}(61 \%$ similarity; our unpublished data). Furthermore, strain NCIMB 9816 can grow at $4{ }^{\circ} \mathrm{C}$ (our unpublished data). These characteristics of strain NCIMB 9816 suggested that this strain belongs to the biovar B group. However, strain NCIMB 9816 could not grow on Ltryptophan and L-kynurenine although it could grow on glucose as a sole carbon source. Whether or not the utilization of these amino acids is a relevant marker to distinguish $P$. putida biovars A and B should be reexamined using larger sets of biovar A and B strains. As an extension of such studies, the reclassification of $P$. putida biovar B strains is highly anticipated.

The strain IFO 3738 was grouped with neither $P$. putida biovar A strains nor biovar B strains in the trees based on $\operatorname{gyr} B$, rpoD and non-variable region of $16 \mathrm{~S}$ rRNA (Fig. 1). Thus, strain IFO 3738 may belong to an unascertained Pseudomonas species having phenotypical and morphological characteristics similar to $P$. putida. To clarify this point, comprehensive phylogenetic analysis of fluorescent group Pseudomonas species should be conducted.

\section{ACKNOWLEDGEMENTS}

We are grateful to Shigeto Miyachi and Kazuhide Yamasato for their encouragement, and to Ikuko Hiramatsu, Satoru Kanai and Hitoshi Ogawa for their technical assistance. This work was supported by Industrial Science and Technology Frontier Program from New Energy and Industrial Technology Development Organization.

\section{REFERENCES}

1. Barnsley, E. A. (1976). Role and regulation of the ortho and meta pathways of catechol metabolism in pseudomonads metabolizing naphthalene and salicylate. $J$ Bacteriol $\mathbf{1 2 5}$, 404 408 .

2. Bochner, B. R. (1989). Sleuthing out bacterial identities. Nature 339, 157-158.

3. Brosius, J., Palmer, M. L., Kennedy, P. J. \& Noller, H. F. (1978). Complete nucleotide sequence of a $16 \mathrm{~S}$ ribosomal RNA gene from Escherichia coli. Proc Natl Acad Sci USA 75, 4801-4805.

4. Burton, Z., Burgess, R. R., Lin, J., Moore, D., Holder, S. \& Gross, C. A. (1981). The nucleotide sequence of the cloned rpoD gene for the RNA polymerase sigma subunit from E. coli K12. Nucleic Acids Res 9, 2889-2903.

5. Dams, E., Hendriks, L., Van de Peer, Y., Neefs, J. M., Smits, G., Vandenbempt, I. \& De Wachter, R. (1988). Compilation of small ribosomal subunit RNA sequences. Nucleic Acids Res 16 (suppl.), r87-r173.

6. Dickerson, R. E. (1971). The structures of cytochrome $c$ and the rates of molecular evolution. $J$ Mol Evol 1, 26-45.

7. Dixon, M. T. \& Hillis, D. M. (1993). Ribosomal RNA secondary structure: compensatory mutations and implications for phylogenetic analysis. Mol Biol Evol 10, 256267.

8. Edwards, U., Rogall, T., Blocker, H., Emde, M. \& Bottger, E. C. (1989). Isolation and direct complete nucleotide determination of entire genes. Characterization of a gene coding for 16S ribosomal RNA. Nucleic Acids Res 17, 7843-7853.

9. Feist, C. F. \& Hegeman, G. D. (1969). Regulation of the meta cleavage pathway for benzoate oxidation by Pseudomonas putida. J Bacteriol 100, 1121-1123.

10. Felsenstein, J. (1989). PHYLIP - phylogeny inference package (version 3.2). Cladistics 5, 164-166.

11. Fitch, W. M. (1971). Toward defining the course of evolution: minimum change for a specific tree topology. Syst Zool $\mathbf{2 0}$, 406-416. 
12. Fox, G. E., Wisotzkey, J. D. \& Jurtshuk, P. J. (1992). How close is close: $16 \mathrm{~S}$ rRNA sequence identity may not be sufficient to guarantee species identity. Int $J$ Syst Bacteriol 42, 166-170.

13. Furukawa, K., Hayase, N., Taira, K. \& Tomizuka, N. (1989). Molecular relationship of chromosomal genes encoding biphenyl/polychlorinated biphenyl catabolism: some soil bacteria possess a highly conserved bph operon. J Bacteriol 171, 5467-5472.

14. Hancock, J. M., Tautz, D. \& Dover, G. A. (1988). Evolution of the secondary structures and compensatory mutations of the ribosomal RNAs of Drosophila melanogaster. Mol Biol Evol 5, 393-414.

15. Johnson, J. L. (1981). Genetic characterization. In Manual of Methods for General Bacteriology, pp. 450-472. Edited by P. Gerhardt, R. G. E. Murray, R. N. Costilow, E. W. Nester, W. A. Wood, N. R. Krieg \& G. B. Philips. Washington, DC: American Society for Microbiology.

16. Jukes, T. H. \& Cantor, C. R. (1969). Evolution of protein molecules. In Mammalian Protein Metabolism, pp. 21-132. Edited by H. N. Munro. New York: Academic Press.

17. Kumar, S., Tamura, K. \& Nei, M. (1993). MEGA: molecular evolutionary genetics analysis, version 1.01. Pennsylvania State University, PA, USA.

18. Lawrence, J. G., Hartl, D. L. \& Ochman, H. (1991). Molecular considerations in the evolution of bacteria genes. $J$ Mol Evol 33, 241-250.

19. Lonetto, M., Gribskov, M. \& Gross, C. A. (1992). The sigma 70 family: sequence conservation and evolutionary relationships. J Bacteriol 174, 3843-3849.

20. Maidak, B. L., Larsen, N., McCaughey, M. J., Overbeek, R., Olsen, G. J., Fogel, K., Blandy, J. \& Woese, C. R. (1994). The ribosomal database project. Nucleic Acid Res 22, 34853487.

21. Molin, G. \& Nilsson, I. (1985). Degradation of phenol by Pseudomonas putida ATCC 11172 in continuous culture at different ratios of biofilm surface to culture volume. Appl Environ Microbiol 50, 946-950.

22. Nagashima, H., Inoue, J., Sasaki, E., Yamamoto, S., Sasaki, Y., Yamauchi-Inomata, Y. \& Harayama, S. (1996). Long-chain nalkanol dehydrogenase from Pseudomonas putida. $J$ Ferment Bioeng 82, 328-333.

23. Nei, M. \& Gojobori, T. (1986). Simple methods for estimating the numbers of synonymous and nonsynonymous nucleotide substitutions. Mol Biol Evol 3, 418-426.

24. Noller, H. F. (1984). Structure of ribosomal RNA. Annu Rev Biochem 53, 119-162.

25. Nurk, A., Kasak, L. \& Kivisaar, M. (1991). Sequence of the gene ( $p h e A$ ) encoding phenol monooxygenase from Pseudomonas sp. EST1001: expression in Escherichia coli and Pseudomonas putida. Gene 102, 13-18.

26. Ochman, H. \& Wilson, A. C. (1987). Evolution in bacteria: evidence for a universal substitution rate in cellular genomes. J Mol Evol 26, 74-86.

27. Olsen, G. J., Woese, C. R. \& Overbeek, R. (1994). The winds of (evolutionary) change: breathing new life into microbiology. J Bacteriol 176, 1-6.

28. Rousset, F., Pelandakis, M. \& Solignac, M. (1991). Evolution of compensatory substitutions through G.U intermediate state in Drosophila rRNA. Proc Natl Acad Sci USA 88, 10032-10036.

29. Saitou, N. \& Nei, M. (1987). The neighbor-joining method: a new method for reconstructing phylogenetic trees. $\mathrm{Mol}$ Biol Evol 4, 406-425.

30. Sambrook, J., Fritsch, E. F. \& Maniatis, T. (1989). Molecular Cloning: a Laboratory Manual, 2nd edn. Cold Spring Harbor, NY: Cold Spring Harbor Laboratory.

31. Schleifer, K.-H. \& Ludwig, W. (1994). Molecular taxonomy: classification and identification. In Bacterial Diversity and Systematics, pp. 1-15. Edited by F. G. Priest, A. RamosCormenzana \& B. J. Tindall. New York: Plenum Press.

32. Shimao, M., Nakamura, T., Okuda, A., Abe, M. \& Harayama, S. (1996). Characteristics of transposon insertion mutants of mandelic acid-utilizing Pseudomonas putida strain A10L. Biosci Biotechnol Biochem 60, 1051-1055.

33. Sokal, R. R. \& Michener, C. D. (1958). A statistical method for evaluating systematic relationships. Univ Kans Sci Bull 28, 1409-1438.

34. Stackebrandt, E. \& Goebel, B. (1994). Taxonomic note: a place for DNA-DNA reassociation and 16S rRNA sequence analysis in the present species definition in bacteriology. Int $J$ Syst Bacteriol 44, 846-849.

35. Stackebrandt, E. \& Liesack, W. (1993). Nucleic acids and classification. In Handbook of New Bacterial Systematics, pp. 151-194. Edited by M. Goodfellow \& A. G. O'Donnell. New York: Academic Press.

36. Stanier, R. Y., Palleroni, N. J. \& Doudoroff, M. (1966). The aerobic pseudomonads : a taxonomic study. J Gen Microbiol 43, 159-271.

37. Takeo, M., Maeda, Y., Okada, H., Miyama, K., Mori, K., Ike, M. \& Fujita, M. (1995). Molecular cloning and sequencing of the phenol hydroxylase gene from Pseudomonas putida $\mathrm{BH}$. $J$ Ferment Bioeng 79, 485-488.

38. Thompson, J. D., Higgins, D. G. \& Gibson, T. J. (1994). CLUSTAL $\mathrm{W}$ : improving the sensitivity of progressive multiple sequence alignment through sequence weighting, position-specific gap penalties and weight matrix choice. Nucleic Acids Res 22, 4673-4680.

39. Watt, P. M. \& Hickson, I. D. (1994). Structure and function of type II DNA topoisomerases. Biochem J 303, 681-695.

40. Williams, P. A. \& Murray, K. (1974). Metabolism of benzoate and the methylbenzoates by Pseudomonas putida (arvilla) mt-2: evidence for the existence of a TOL plasmid. $J$ Bacteriol 120, 416-423.

41. Woese, C. R. (1987). Bacterial evolution. Microbiol Rev 51, 221-271.

42. Yamagishi, J., Yoshida, H., Yamayoshi, M. \& Nakamura, S. (1986). Nalidixic acid-resistant mutations of the $\operatorname{gyr} B$ gene of Escherichia coli. Mol Gen Genet 204, 367-373.

43. Yamamoto, S. \& Harayama, S. (1995). PCR amplification and direct sequencing of $\operatorname{gyr} B$ genes with universal primers and their application to the detection and taxonomic analysis of Pseudomonas putida strains. Appl Environ Microbiol 61, 1104-1109.

44. Yen, K. M. \& Gunsalus, I. C. (1985). Regulation of naphthalene catabolic genes of plasmid NAH7. J Bacteriol 162, 1008-1013. 